\title{
Effects of low-level laser therapy on bone healing of critical-size defects treated with bovine bone graft
}

\author{
Alvaro Francisco Bosco a , Paula Lazilha Faleiros ${ }^{a}$, Luana Rodrigues Carmona ${ }^{\text {a }}$ \\ Valdir Gouveia Garcia ${ }^{\mathrm{a}, \mathrm{b}}$, Letícia Helena Theodoro ${ }^{\mathrm{a}}$, Nathália Januario de Araujo ${ }^{\mathrm{a}}$, \\ Maria José Hitomi Nagata ${ }^{a}$, Juliano Milanezi de Almeida ${ }^{\mathrm{a}, *}$

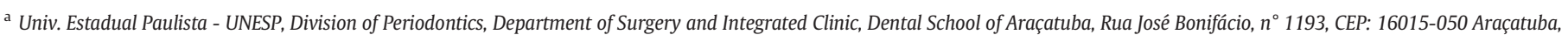 \\ São Paulo, Brazil

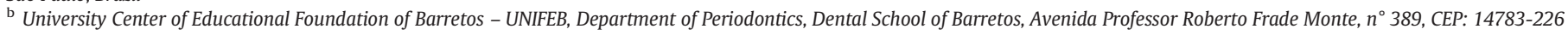 \\ Barretos, São Paulo, Brazil
}

\section{A R T I C L E I N F O}

\section{Article history:}

Received 3 June 2016

Accepted 25 August 2016

Available online 31 August 2016

\section{Keywords:}

Bone grafting

Bone regeneration

Calvaria

Low-level laser therapy

\begin{abstract}
A B S T R A C T
Objective: To histomorphometrically analyze the effect of low-level laser therapy (LLLT) on bone formation process in surgically created critical-size defects (CSDs) treated with bovine bone graft (BBG) and its influence over particles' resorption of BBG.

Methods: A 10-mm diameter CSD was surgically created in the calvaria of 64 male rats, which were distributed into 4 experimental groups: the C group (control), only blood clot; the LLLT group, LLLT (GaAlAs, $660 \mathrm{~nm}$ ) and blood clot; the BBG group, CSD filled with BBG; the BBG/LLLT group, LLLT and CSD filled with BBG. Animals were euthanized at either 30 or 60 days post-operation. A histological analysis was performed. Additionally, the percentage of newly formed bone area (NFBA) and remaining particles areas (RPA) of BBG were histometrically evaluated and data statistically analyzed.

Results: The LLLT $(5.82 \pm 2.05 ; 7.34 \pm 1.01)$ group presented significantly greater NFBA when compared to the $C$ group $(1.61 \pm 0.30 ; 5.59 \pm 0.94)$ at 30 and 60 days post-operation $(p<0.05)$. The BBG/LLLT group ( $7.39 \pm 1.45$; $9.44 \pm 2.36)$ presented significantly greater NFBA than the BBG group $(3.85 \pm 1.56 ; 8.02 \pm 0.63)$ at 30 and 60 days postoperation $(p<0.05)$. There was no significant difference in the mean percentage of implanted material RPA between the BBG and the BBG/LLLT groups.

Conclusions: LLLT can improve bone formation process in CSD filled or not with BBG in rat calvaria, but it is not able to accelerate particles resorption of this material in the interior of bone defect.
\end{abstract}

(c) 2016 Elsevier B.V. All rights reserved.

\section{Introduction}

Bone loss in the maxillofacial region presents a challenging clinical issue, especially in the case of large defects, where their physiological regenerative capability is exceeded [1]. A variety of bone grafting or substitutes $[2,3,4,5]$ have been suggested in order to regenerate these defects [6].

Among the materials used for bone regeneration, autogenous bone has been considered the ideal graft material $[7,8,9]$ because of its

\footnotetext{
* Corresponding author at: Departamento de Cirurgia e Clinica Integrada, Disciplina de Periodontia, Faculdade de Odontologia de Araçatuba, UNESP, Rua José Bonifácio, 1193, CEP: 16015-050 Araçatuba, São Paulo, Brazil.

E-mail addresses: afbosco@hotmail.com (A.F. Bosco), paulal.faleiros@hotmail.com (P.L. Faleiros), luanarcarmona@yahoo.com.br (L.R. Carmona), vg.garcia@uol.com.br (V.G. Garcia), letheodoro@uol.com.br (L.H. Theodoro), nathaliajanuario@outlook.com (N.J. de Araujo), mjnagata@uol.com.br (M.J.H. Nagata), jumilanezi@hotmail.com (J.M. de Almeida)
}

osteoinductive, osteoconductive, and osteogenic characteristics [10]. However, its collection is associated with significant donor site morbidity, including damage to anatomic structures [11], infections [11,12], pain $[13,14]$, hematoma formation [12,15], and unpredictable graft resorption $[7,8,16]$. Obtaining bone tissue from donor site sufficient to fill the defect also becomes a challenge in some complex clinical conditions that require bone regeneration in large quantity, such as bone defects resulting from trauma, infection, tumor resection, skeletal abnormalities, atrophic non-unions and osteoporosis conditions [17]. Moreover, grafts are often resorbed before osteogenesis is finished in large defects [15].

Consequently, a search for bone biomaterials that could replace the autologous bone, with the advantages of unlimited supply and no need for a donor site [16], has taken place [10]. Nonetheless, these are not always graced with the advantages of osteogenesis and osteoinduction inherent of the autologous grafts $[10,18]$. Xenogeneic bovine bone grafts (BBG) are the most commonly used material [19, 
$20,21,22,23]$. The literature reports its superior biocompatibility and osteoconductivity compared to other bone substitutes [19,22]. However, this material still lacks factors that promote osteogenesis and osteoinduction [10]. In turn, this increases healing time compared to autologous bone, which feature live cells and growth factors, fulfilling their osteogenic and osteoinductive potentials [18]. Such properties reflect positively on the time required for bone healing [24].

Low-level laser therapy (LLLT) has emerged as a strategy to accelerate the healing of bone defects treated with xenogeneic BBG [16,23] and others bone substitutes materials [25], since it can acts as an osteoinductive factor $[26,27]$. The exact mechanism of action of LLLT on bone healing is not well understood [23], but it has been reported that it can promote angiogenesis [28] and increase local blood flow (enhancing the supply of circulating cells, nutrition, oxygen, and inorganic salts to the bone defect) [29], stimulate cell growth such as fibroblasts (which are related to collagen production) [30], increase osteoblast proliferation and differentiation [31] and promote mitochondrial respiration and ATP synthesis [32]. Specifically regarding xenogeneic BBG, there is a report that LLLT can improve bone formation process and accelerate particles resorption in the interior of bone defects [16], since it can increases osteoblastic [33] and osteoclastic activity [34]. This is a valuable finding when particles fail to resorb and remain like a motionless body surrounded by the host bone [35,36].

Few studies have addressed the action of LLLT on the interaction of implanted biomaterial and tissue during bone healing process $[37,38]$. It has been shown that LLLT promotes bone healing and bone mineralization [39]. In the search for the optimal biomaterials tissue interaction, the effect of LLLT on these cells is an important field of investigation [39]. Thus, the purpose of the present study was to analyze histomorphometrically the effect of LLLT on bone formation process in surgically created critical-size defects (CSDs) treated with BBG and its influence over particles resorption of BBG.

\section{Materials and Methods}

\subsection{Animals and Experimental Groups}

After careful planning of a double-blind interventional animal study and an ethical approval by the Ethics Committee on Animal Use (protocol \# 003162/2007) of the School of Dentistry, Araçatuba Campus, São Paulo State University, sixty four 3-month-old male rats (Rattus norvegicus, albinus, Wistar) weighing 250 to 300 g (UNESP, Dental School of Araçatuba, Animal Care Unit) were included in the study. This study conforms to ARRIVE (Animal Research: Reporting of In Vivo Experiments) [40]. The animals were kept in plastic cages with access to food and water ad libitum, in a room with a 12-h light/dark cycle and a temperature between 22 and $24^{\circ} \mathrm{C}$. Prior to surgical procedures, all animals were allowed to acclimatize to the laboratory environment for a period of 7 days. Following a table generated by a computer program, the animals were distributed into 4 experimental groups ( $n=$ 16): the C group (control), only blood clot; the LLLT group, LLLT and blood clot; the BBG group, CSD filled with BBG; BBG/LLLT group, LLLT and CSD filled with BBG.

\subsection{Creation of the CSD}

For surgical procedures, the animals were anesthetized by intramuscular injection with ketamine $(70 \mathrm{mg} / \mathrm{kg}$ ) (Vetaset, Zoetis, Florham Park, NJ) and xylazine (6 mg/kg) (Coopazine, Coopers, São Paulo, São
Paulo, Brazil). After aseptic preparation, a semilunar incision was made in the scalp in the anterior region of the calvarium, allowing reflection of a full thickness flap in a posterior direction. A 10-mm CSD was made with a trephine ( 3 i Implant Innovations Inc., FL, USA) in a low-speed hand piece under continuous sterile saline irrigation. Extreme care was taken not to damage the dura mater during the creation of the CSD. The defect included a portion of the sagittal suture. The CSD of each animal was filled with particles of 250 to $1000 \mu \mathrm{m}$ of BBG (GenMix Baumer S.A., São Paulo, SP, Brazil) using a $6 \mathrm{~mm}^{3}$ measuring cup [6]. The soft tissues were then repositioned and sutured (4-0 Silk; Ethicon, São Paulo, SP, Brazil) to achieve primary closure. Each animal received post-surgical intramuscular injections of 24.000 IU of penicillin Gbenzathine (Fort Dodge, Saúde Animal Ltd., Campinas, SP, Brazil).

\subsection{LLLT Protocol}

In the LLLT and BBG/LLLT groups the LLLT was used after the displacement of the total retail and clothing of the surgical defect. The laser used in this study was gallium aluminum-arsenide (Bio Wave; Kondortech Equipment Ltd., São Carlos, São Paulo, Brazil), with a wavelength of $660 \mathrm{~nm}$, power of $35 \mathrm{~mW}$, and spot size of $0.07 \mathrm{~cm}^{2}$. LLLT was performed once in eight points around the CSD, in contact with the bone tissue, and also in a central point of the CSD in the scanning procedure [41]. The treatment laser was emitted with power of $0.03 \mathrm{~W}$ during $72 \mathrm{~s} /$ point, irradiance of $0.42 \mathrm{~W} / \mathrm{cm}^{2}$, and fluency of $30.85 \mathrm{~J} / \mathrm{cm}^{2} /$ point. The area received a total energy of $19.44 \mathrm{~J}$.

\subsection{Tissue Processing}

Eight animals from each group were euthanized at 30 or 60 days post-operation. The area of the original surgical defect and the surrounding tissues were removed in block. The blocks were fixed in $4 \%$ paraformaldehyde in $0.1 \mathrm{M}$ phosphate buffer ( $\mathrm{pH} 7.4$ ) for $48 \mathrm{~h}$, rinsed with water, and then demineralized in a solution of $10 \%$ EDTA. After decalcification, they were processed and embedded in paraffin. Serial $6 \mathrm{~mm}$-thick sections were cut in a longitudinal direction. The sections were stained with hematoxylin and eosin (H\&E) for analysis under light microscopy. Two sections from the central area were selected for histological and histometric analyses.

\subsection{Histomorphometric Analysis}

Two histological sections, representing the center of the original surgical defect, were selected for histologic and histometric analyses to increase the reliability of the data used in the statistical analysis. These analyses were performed by an examiner blinded to the treatment rendered (LRC). The images of the histologic sections were captured by a digital camera (Olympus DP 10, Olympus Optical Co. Ltd., Tokyo, Japan) coupled to a light microscope (Olympus BX 50 F4, Olympus Optical Co. Ltd., Tokyo, Japan) with an original magnification of $32 \times$. The digital images were saved on a computer. A composite digital image was then created by combining three smaller images, because it was not possible to capture the entire defect in one image at the level of magnification used. The composite image was created based on anatomic reference structures (such as blood vessels and bone trabeculae) within each of the histologic sections. The Imagelab 2000 software (Diracon Bio Informática Ltd., Vargem Grande do Sul, São Paulo, Brazil) was used for the histomorphometric analysis. The following criteria [42]

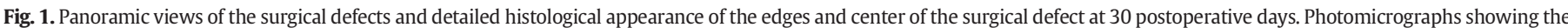

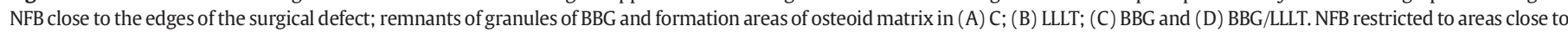

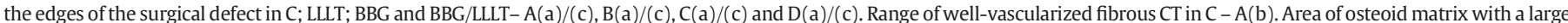

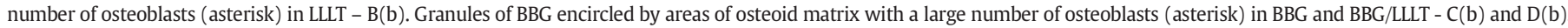

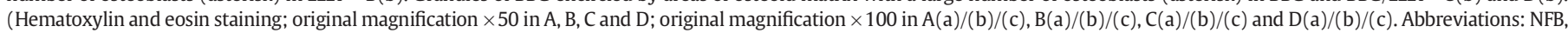
newly formed bone; $\mathrm{BBG}$, bovine bone graft; $\mathrm{CT}$, conjunctive tissue. 

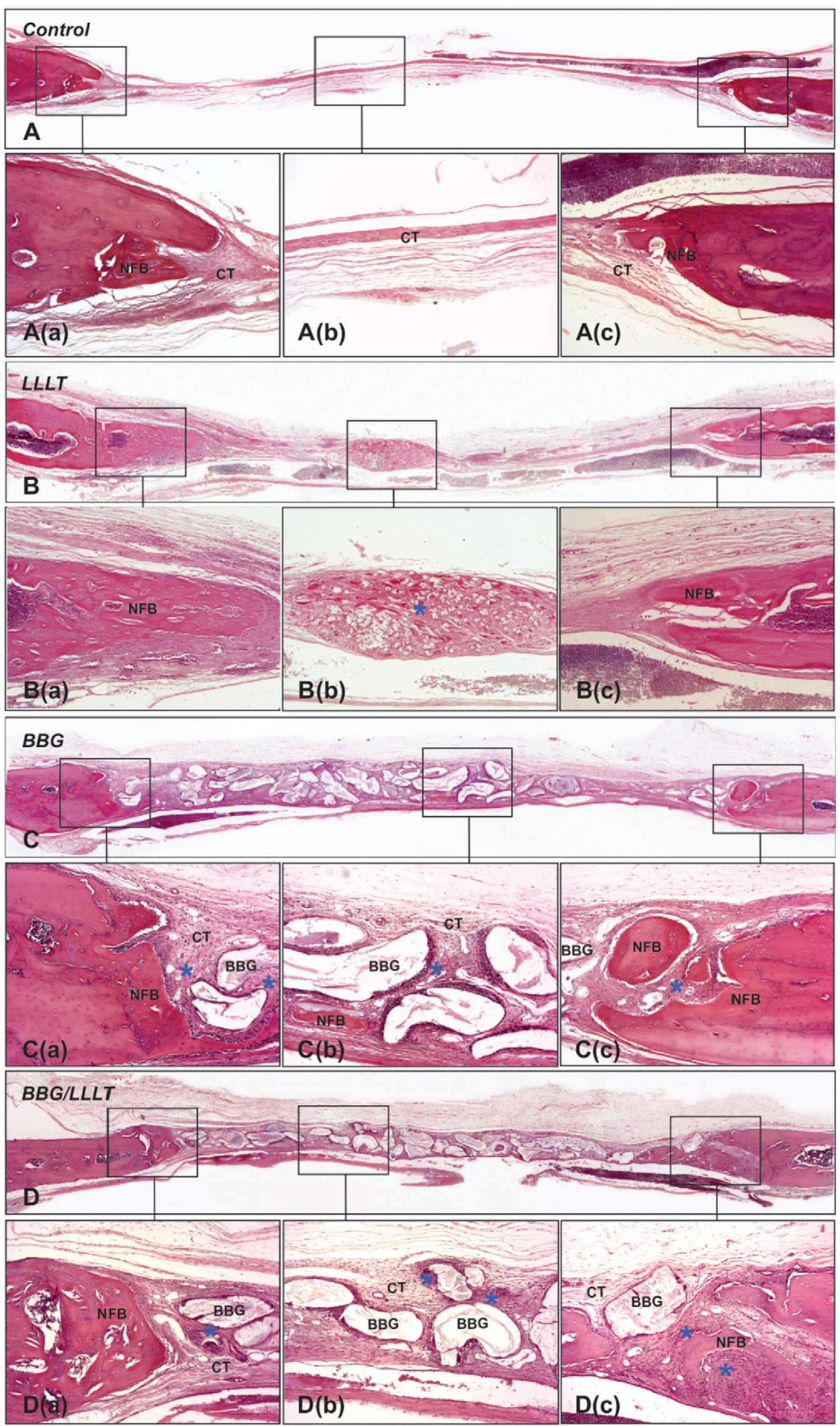
were used to standardize the histomorphometric analysis of the digital images:

(a) The total area to be analyzed corresponded to the entire area of the original surgical defect. This area was determined by first identifying the external and internal surfaces of the original calvarium at the right and left margins of the surgical defect, and then connecting them with lines drawn following their respective curvatures. The newly formed bone area (NFBA) was delineated within the confines of the total area.

(b) The total area was measured in square millimeters and was considered to represent $100 \%$ of the area to be analyzed. The NFBA and remaining particles areas (RPA) of BBG was also measured in square millimeters and calculated as a percentage of the total area.

\subsection{Statistical Analysis}

The values of NFBA for each animal were represented by the mean percentage of the two histologic sections. The data were subjected to the Shapiro-Wilk test to confirm a normal distribution, and the data were analyzed by a two-way ANOVA $(p \leq 0.05)$ with Tukey's post hoc test for individual comparisons $(p \leq 0.05)$. All analyses were performed using BioStat 3.0 software (Bioestat Windows 1995 Sonopress; Manaus, Amazonas, Brazil).

\section{Results}

\subsection{Qualitative Histologic Analysis}

At 30 days post-operation, almost all specimens of the $C$ group exhibited absence of new bone formation at the edges of surgical defect while some specimens exhibited discrete new bone formation (Fig. 1: $\mathrm{A}(\mathrm{a}) /(\mathrm{c}))$. The connective tissue presented thin and with rare fibroblasts (Fig. 1: $A(b)$ ). In the LLLT group, we observed discrete new bone formation at the edges of surgical defect (Fig. 1: B(a)/(b)). Inside it, the collagen fibers of connective tissue presented more organized than the $C$ group and with small number of fibroblasts. Areas of osteoid matrix with a large number of osteoblasts also were observed (Fig. 1: B(b)). The BBG and BBG/LLLT groups exhibited extensive areas occupied by implanted material (Fig. 1: C, D) encircled by a range of wellvascularized fibrous and osteoid matrix with a large number of osteoblasts (Fig. 1: $\mathrm{C}(\mathrm{b}), \mathrm{D}(\mathrm{b})$ ). In the BBG group also was observed discrete new bone formation at the edges of surgical defect (Fig. 1: C(a)/(c)) and the presence of small spurs of new bone formation adjacent to implanted material in the interior of defect (Fig. 1: C(b)). In the BBG/LLLT group was observed discrete new bone formation at the edges of surgical defect (Fig. 1: D(a)/(c)), however, higher than BBB and the LLLT groups. The interior of defect presented connective tissue with moderated number of fibroblasts and osteoid matrix with a large number of osteoblasts adjacent to implanted material (Fig. 1: D(b)).

At 60 days post-operation, the histological characteristics were similar to those previously described. All specimens of $C$ group presented similar characteristics in relation to connective tissue and arrangement of collagen fibers, which exhibited a moderate number of fibroblasts dispersed throughout the defect (Fig. 2: A(b)). In the LLLT group was observed areas of new bone formation at the edges (Fig. 2: $\mathrm{B}(\mathrm{a}) /(\mathrm{b})$ ) and inside the surgical defect (Fig. 2: B(b)). In BBG and BBG/LLLT groups, the interior of defect was occupied by granules of implanted material (Fig. 2: C, D), without an extensive inflammatory response (Fig. 2: $C(b), D(b))$. With respect to bone formation, the histological characteristics of the C, LLLT and BBG groups were very similar to 30 days post- operation. The specimens of the BBG/LLLT group presented moderated new bone formation at the edges of surgical defect (Fig. 2: D(a)/(c)) and e more quantity of new bone formation spurs adjacent to implanted material (Fig. 2: D(c)) compared to C, LLLT and the BBG groups. The BBG and BBG/LLLT groups presented specimens with granules of BBG encircled by new bone formation and extensive areas of osteoid matrix formation with large number of osteoblasts (Fig. 2: C(b), D(b)/(c)). No CSD in any of the groups and time points studied were completely regenerated with bone. At the end of the experimental period, the defect in the BBG and BBG/LLLT groups was still filled by BBG and the area was densely filled by collagen fibers.

\subsection{Histometric Analyses}

\subsubsection{NFBA}

The LLLT $(5.82 \pm 2.05 ; 7.34 \pm 1.01)$ group presented significantly greater NFBA when compared to the $C$ group $(1.61 \pm 0.30 ; 5.59 \pm$ $0.94)$ at 30 and 60 days post-operation $(p<0.05)$. The BBG/LLLT group $(7.39 \pm 1.45 ; 9.44 \pm 2.36)$ presented significantly greater NFBA when compared to the BBG group ( $3.85 \pm 1.56 ; 8.02 \pm 0.63)$ at 30 and 60 days post-operation $(p<0.05)$. Means and standard deviations of NFBA for each group are presented in Table 1.

\subsection{2. $R P A$}

Comparison between periods within the same group showed that solely BBG Group showed lower $(p \leq 0,05)$ mean RPA percentage for the implanted material following 60 post-operation days $(22.72 \pm$ 10.23 ) when compared to 30 post-operation days (27.78 \pm 11.22 ). BBG/LLLT Group did not present any statistically meaningful difference in mean RPA percentage of implanted material in $30(21.98 \pm 4.10)$ and $60(27.20 \pm 6.39)$ post-operation days. There was no statistically meaningful difference at the mean RPA percentage of implanted material between groups at the same period. Mean and standard deviations of RPA, with inter and intra-groups comparisons, are presented at Table 2 .

\section{Discussion}

This study used the classical calvarial defect model [43] to evaluate, from a histological and histometric point of view, the effect of LLLT on bone healing processes of surgically created CSDs treated with BBG. Considering previous findings about the action of LLLT on osteoblastic [33] and osteoclastic activity [34], our hypotheses were: (1) LLLT could improve bone formation process; (2) LLLT could accelerate the particles resorption of BBG in the interior of the bone defects.

In the present study, in both experimental periods, the LLLT group presented greater new bone formation when compared to $\mathrm{C}$ (control) group, and the BBG/LLLT group presented greater new bone formation when compared to BBG group, suggesting that LLLT can increase the bone formation and accelerate the bone healing process in CSDs treated or not with BBG. These results are in agreement with previous studies that support the positive effect of laser on bone formation both when used alone or associated with bone graft $[16,23]$. The literature reports that bone healing process triggered by injury results in a local inflammatory immune reaction whose development is thought to highly influence the outcome of such process $[44,45,46]$. The inflammatory events contribute to the local production/release of growth factors classically associated with bone neoformation, as well with the promotion of chemotaxis of cells associated with the repair process [46,47,48,49,50,51]. It

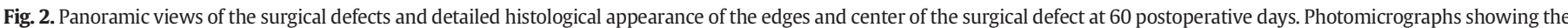

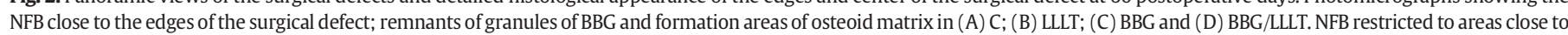

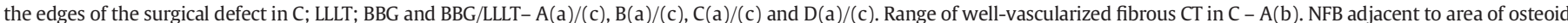

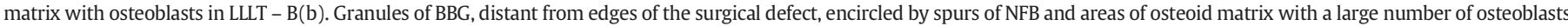

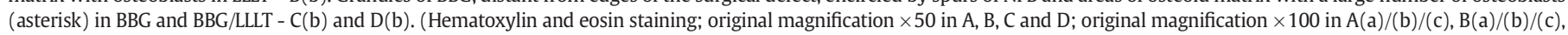
$\mathrm{C}(\mathrm{a}) /(\mathrm{b}) /(\mathrm{c})$ and $\mathrm{D}(\mathrm{a}) /(\mathrm{b}) /(\mathrm{c})$. Abbreviations: NFB, newly formed bone; BBG, bovine bone graft; $\mathrm{CT}$, conjunctive tissue. 

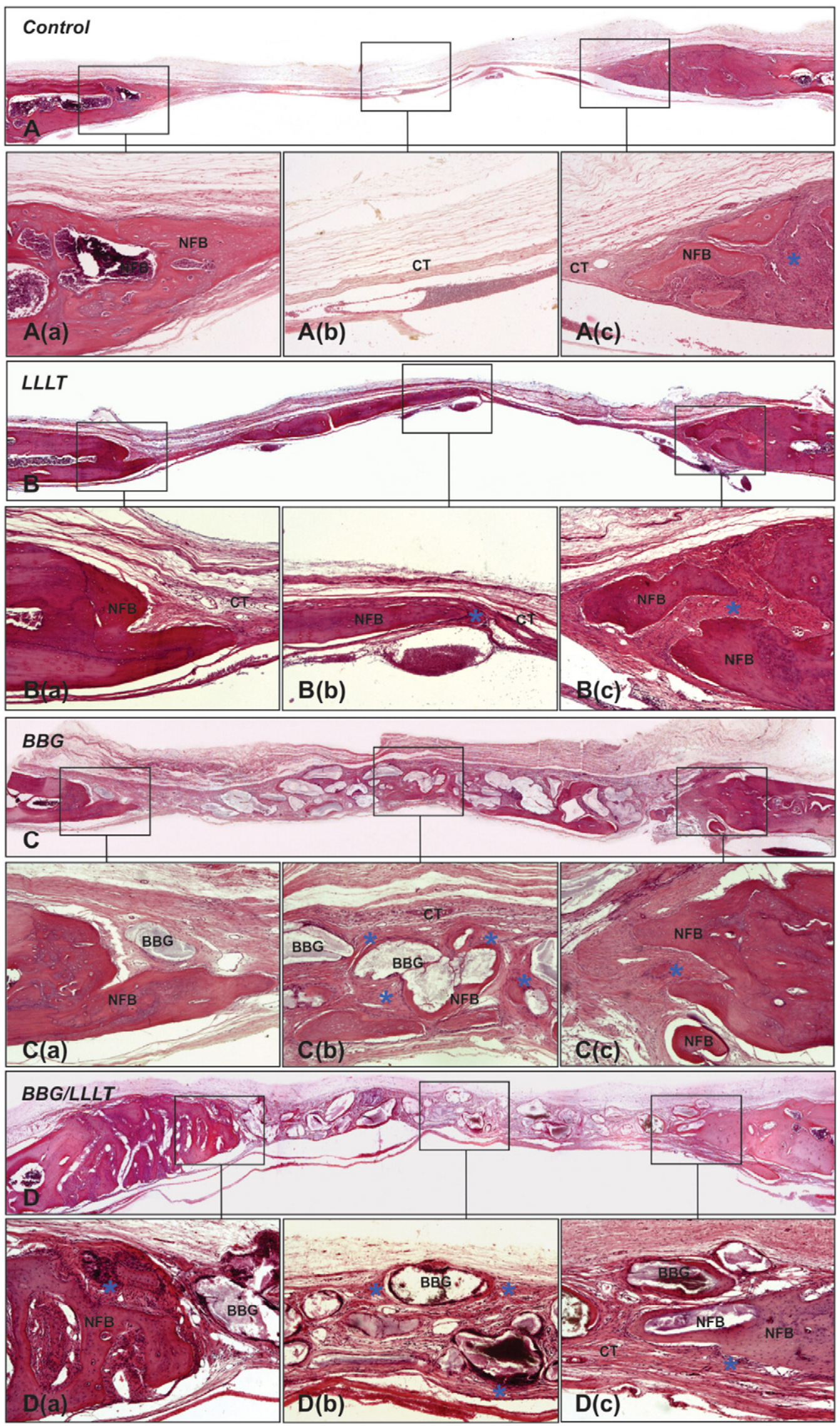
Table 1

Mean percentage (\%) and standard deviations $(M \pm S D)$ of NFBA within the surgically created defects with comparison among groups.

\begin{tabular}{llll}
\hline & & Periods \\
\cline { 3 - 4 } Groups & $\mathrm{n}$ & 30 days & 60 days \\
\hline C (control) & 16 & $1.61 \pm 0.30$ & $5.59 \pm 0.94$ \\
LLLT & 16 & $5.82 \pm 2.05^{*}$ & $7.34 \pm 1.01^{*}$ \\
BBG & 16 & $3.85 \pm 1.56^{*}$ & $8.02 \pm 0.63^{*}$ \\
BBG/LLLT & 16 & $7.39 \pm 1.45^{*}, \#$ & $9.44 \pm 2.36^{*}, \#$ \\
n & 64 & 32 & 32 \\
\hline
\end{tabular}

Comparison inter-groups.

* Significant difference with C group (ANOVA, Tukey's test) $(p<0.05)$.

\# Significant difference with BBG group (ANOVA, Tukey's test) $(p<0.05)$.

was reported that the LLLT can increase vascularization and early onset of the inflammatory response, which is resolved more rapidly. This event allows that the proliferation phase of healing begins earlier [52]. In addition, the bone defect healing depends on the availability of precursor cells in the surrounding bone or soft tissue, and also the ability of these cells to invade the defect and to differentiate into fibroblasts and osteoblasts [23]. It is not clear whether the LLLT biomodulation of bone formation is a consequence of mesenchymal cells stimulation [53] or direct stimulation of osteoblastos [54], but may be that it results from an increased release of fibroblast growth factor, which is found in bone tissue and acts on differentiated cells, increasing cell proliferation and secretion of bone matrix components [55].

The collagen fibers are organic precursors of extracellular matrix and act as a scaffold for ions deposition on bone mineralization process [56]. In the present study, the qualitative histological analysis demonstrated that collagen fibers of connective tissue presented more organized in LLLT than the C group, suggesting a biostimulatory effect of LLLT in the collagen production. Similar results were also previously reported [57, $58,59]$. Ultimately, the literature also showed that the LLLT can improve the capability of mature osteoblasts to release calcium hydroxyapatite [60]. During early stages of healing, the osteoblastic activity was chiefly proliferative and deposition started later, which resulted in the formation of immature bone, still poor in hydroxyapatite crystals [60]. The hydroxyapatite crystals are found on collagen fibers, within them, and in the matrix around and the deposition of this mineral represents bone maturation [60]. The LLLT combined with bone graft and guided bone regeneration increases calcium hydroxyapatite concentrations improving defects bone healing than using bone graft only $[59,60]$. These results are in agreement with those obtained in the present study since it was observed greater new bone formation in the specimens of the $\mathrm{BBG} / \mathrm{LLLT}$ group in comparison to the BBG group. Despite of this finding, the literature presents controversial results [55].

The different doses, application protocols and experimental models complicate comparisons between the studies. Many variables may affect the LLLT biostimulatory effects (such as, laser wavelength, energy, exposition time, power, and the biologic state of the cell). Most studies have evaluated the effect of infrared laser light on bone healing [59,61, $62,63,64]$ because of its tissues deeper penetration. However, recent studies of Garcia et al. $[38,41]$ have demonstrated that visible laser light (660 nm wavelength) also presents biomodulatory effect on

\section{Table 2}

Mean percentage (\%) and standard deviations $(\mathrm{M} \pm \mathrm{SD}$ ) of RPA within the surgically created defects with comparison among groups.

\begin{tabular}{llll}
\hline & & Periods & \\
\cline { 3 - 4 } Groups & $\mathrm{n}$ & 30 days & 60 days \\
\hline BBG & 16 & $27.78 \pm 1.12$ & $22.72 \pm 1.02^{*}$ \\
BBG/LLLT & 16 & $21.98 \pm 4.10$ & $27.20 \pm 6.39$ \\
$\mathrm{n}$ & 32 & 16 & 16
\end{tabular}

* Significant difference with BBG group in the same period (ANOVA, Tukey's test) $(p \leq 0.05)$. bone healing, when used transoperatively at the borders of surgical defect, in contact with bone tissue, and also in a central point of the CSD $[38,41]$. On the contrary, Jakse et al. [65] did not confirm the positive LLLT effect on bone healing in cancellous sinus graft, because of it inadequate irradiation power $\left(<4 \mathrm{~J} / \mathrm{cm}^{2}\right)$ and absorption of most irradiated light by thick sinus cortical bone and deep sinus of the sheep. In both studies of Garcia et al. [38,41], the CSD was irradiated only during the surgery procedure. As in the mentioned studies, in the present, the CSD also was irradiated with visible laser light ( $660 \mathrm{~nm}$ of wavelength, $30.85 \mathrm{~J} / \mathrm{cm}^{2}$ of dose), only during the surgical procedure at the borders of wound, in contact with bone tissue, and also in a central point of the surgical defect.

Although the use of LLLT on the biostimulation of bone repair has been growing steadily, and several studies have demonstrated positive results on the healing of bone tissue, there are few previous reports on the association of LLLT and bone grafts or biomaterials [55,66]. Some preclinical studies have demonstrated the effects of LLLT on implanted biomaterials in order to improve bone healing process in different models of study with bone augmentation procedures. Among the models used are: calvarial CSDs [16,23,38,62], surgical defects created in femur [59,67], tibiae fractures [68], mandibular trauma [69] and titanium implants associated to biomaterial on tibiae of rats $[60,68]$.

The calvarial bone defect model is appropriate for the examination of maxillary bone regeneration because its several similarities to the maxillofacial area [70,71]. Anatomically, the calvarium consists of two cortical sheets separated by reticulated bone, like the mandible; physiologically, the healing pattern is also similar to that of the maxillae [72]. In terms of morphology and embryology, the calvarium develops from a precursor membrane, like the bones of the face, including the maxilla and the mandible [73,74]. This process is called intramembranous bone formation because it occurs in the interiors of the membranes of loose connective tissue and not on a cartilaginous mold, which characterizes endochondral ossification [75]. Once the graft is placed within the calvarial surgical defect, the particles of material are engulfed by a blood clot. This supplies the necessary proteins/ growth factors needed to begin the cell adhesion process and ultimately the reconstruction and repairing of bone [6].

The qualitative histological analysis demonstrated that, excepting for some specimens of control group at 30 days post-operation, new bone formation was observed close to the borders of the surgical defect. In the groups treated with $\mathrm{BBG}$, it was possible to observe particles encircled by immature bone trabeculae or collagen fibers with no signs of an extensive inflammatory response, suggesting that the grafting material placed in the defects was biocompatible and, at the same time, osteoconductive. However, either in the BBG or BBG/LLLT group, the particles remained within the defect. This observation is important because of the reports that LLLT can accelerate the resorption of these particles in the interior of bone defects [16]. In the present study, the quantitative histological analysis showed that while in the BBG group there was a decrease in the mean percentage of implanted material particles over the time, in the BBG/LLLT group it didn't occurred. It was also observed that there was no significant difference in the mean percentage of particles between these two groups in both experimental periods studied. These results suggest that, on the contrary reported by Cunha et al. [16] LLLT is not able to accelerate particles resorption of BBG. Despite these findings, these materials have been used successfully in numerous clinical and preclinical studies, including guided bone regeneration [76,77], sinus augmentation [78,79] and socket augmentation [80,81]. Considering that little is known about the effects of LLLT on xenogenics BBG and the high rate in medical and dental clinics of theses material in bone reconstruction procedures, we believe that the present study has important implications in the clinical setting.

Within the limits of the present study, it can be concluded that LLLT can improve bone formation process in CSD filled or not with BBG in rat calvaria, but it is not able to accelerate particles resorption of this material in the interior of bone defect. 


\section{Acknowledgments}

The authors thank the São Paulo State Foundation for Research for granting a scholarship to Luana Rodrigues Carmona (FAPESP \#07/ 05896-1). The authors thank Professor Tetuo Okamoto (Department of Surgery and Integrated Clinic, Division of Surgery, São Paulo State University Júlio de Mesquita Filho UNESP, Araçatuba, São Paulo, Brazil) for his assistance with the histological analysis (in memoriam). The authors declare no conflicts of interest or financial relationships to any products involved in this study.

\section{References}

[1] K.J. Burg, S. Porter, J.F. Kellam, Biomaterial developments for bone tissue engineering. Biomaterials 21 (23) (2000) 2347-259.

[2] P. Lichte, H.C. Pape, T. Pufe, P. Kobbe, H. Fischer, Scaffolds for bone healing: concepts, materials and evidence, Injury 42 (6) (2011) 569-573.

[3] S. Agacayak, B. Gulsun, M.C. Ucan, E. Karaoz, Y. Nergiz, Effects of mesenchymal stem cells in critical size bone defect, Europ. Rev. Med. Pharmacol. Sci. 16 (5) (2012) 679-686.

[4] T. Liu, G. Wu, D. Wismeijer, Z. Gu, Y. Liu, Deproteinized bovine bone functionalized with the slow delivery of BMP-2 for the repair of critical-sized bone defects in sheep, Bone 56 (1) (2013) 110-118.

[5] J.R. Ferreira, R. Padilla, G. Urkasemsin, K. Yoon, K. Goeckner, W.S. Hu, et al., Titaniumenriched hydroxyapatite-gelatin scaffolds with osteogenically differentiated progenitor cell aggregates for calvaria bone regeneration, Tissue Eng. A 19 (15-16) (2013) $1803-1816$

[6] J.M. de Almeida, A.F. Bosco, P.L. Faleiros, V.F. Pazmiño, A.C. Murakawa, S. Bonfante, M.J. Nagata, V.G. Garcia, Effects of oestrogen deficiency and 17/-estradiol therapy on bone healing in calvarial critical size defects treated with bovine bone graft, Arch. Oral Biol. 60 (4) (2015) 631-641.

[7] M. Hallman, A. Thor, Bone substitutes and growth factors as an alternative/complement to autogenous bone for grafting in implant dentistry, Periodontology 47 (1) (2008) 172-192.

[8] G.F. Rogers, A.K. Greene, Autogenous bone graft: basic science and clinical implications, J. Craniomaxillofac. Surg. 23 (1) (2012) 323-327.

[9] C.M. Schmitt, H. Doering, T. Schmidt, R. Lutz, Neukam WF, Schlegel KA, Histological results after maxillary sinus augmentation with Straumann BoneCeramic, Bio-Oss, Puros, and autologous bone. A randomized controlled clinical trial, Clin. Oral Implants Res. 24 (5) (2013) 576-585.

[10] P.J. Pasquali, M.L. Teixeira, T.A. de Oliveira, L.G. de Macedo, A.C. Aloise, A.A. Pelegrine, Maxillary sinus augmentation combining Bio-Oss with the bone marrow aspirate concentrate: a histomorphometric study in humans, Int. J. Biomater. 2015 (2015) 121286 .

[11] S. Herford, J. Dean, Complications in bone grafting, Oral Maxillof. Surg. Clin. N. America 23 (3) (2011) 433-442.

[12] P.V. Giannoudis, H. Dinopoulos, E. Tsiridis, Bone substitutes: an update, Injury 36 (3) (2005) S20-S27.

[13] P. Amerio, G. Vianale, M. Reale, R. Muraro, A. Tulli, A. Piattelli, The effect of deproteinized bovine bone on osteoblast growth factors and proinflammatory cytokine production, Clin. Oral Implants Res. 21 (6) (2010) 650-655.

[14] L. Ohayon, Ridge enlargement using deproteinized bovine bone and a bioresorbable collagen membrane: a tomodensitometric, histologic, and histomorphometric analysis, Int. J. Period. Restor. Dentis. 31 (3) (2011) 237-245.

[15] K.L.B. Brown, R.L. Cruess, Bone and cartilage transplantation surgery, J. Bone Joint Surg. 64 (1982) 270-279

[16] M.J. Cunha, L.A. Esper, Sbrana MC, de Oliveira PG, do Valle AL, de Almeida AL, Effect of low-level laser on bone defects treated with bovine or autogenous bone grafts: in vivo study in rat calvaria, Biomed. Res. Int. 2014 (2014) 104230.

[17] R. Dimitriou, et al., Bone regeneration: current concepts and future directions, BMC Med. 9 (2011) 66-76.

[18] D.J. Prolo, J.J. Rodrigo, Contemporary bone graft physiology and surgery, Clin. Orthop. Relat. Res. 200 (1985) 322-342.

[19] A. Stauropoulos, L. Kostopoulos, J.R. Nyengaard, T. Karring, Deproteinized bovine bone (Bio-Oss) and bio active glass (Biogram) arrest bone formation when used as an adjust to guided tissue regeneration (GTR): an experimental study in the rat, J. Clin. Periodontol. 30 (7) (2003) 636-643.

[20] G. Zucchelli, C. Amor, L. Montebugnoli, M. De Sanctis, Enamel matrix proteins and bovine porous bone mineral in the treatment of intra bony defects: a comparative controlled clinical trial, J. Periodontol. 74 (12) (2003) 1725-1735.

[21] A. Scarano, G. Pecora, M. Piattelli, A. Piattelli, Osseointegration in a sinus augmented with bovine porous bone mineral: histological results in an implant retrieved 4 years after insertion. A case report, J. Periodontol. 75 (8) (2004) 1161-1166.

[22] G. Iezzi, A. Scarano, C. Mangano, B. Cirotti, A. Piattelli, Histologic results from human implant retrieved due to fracture 5 years after insertion in a sinus augmented with an organic bovine bone, J. Periodontol. 79 (1) (2008) 192-198.

[23] A.A. Rasouli Ghahroudi, A.R. Rokn, K.A. Kalhori, A. Khorsand, A. Pournabi, A.L Pinheiro, R. Fekrazad, Effect of low-level laser therapy irradiation and Bio-Oss graft material on the osteogenesis process in rabbit calvarium defects: a double blind experimental study, Lasers Med. Sci. 29 (3) (2014) 925-932.

[24] N. Esfahanizadeh, A.R. Rokn, M. Paknejad, P. Motahari, H. Daneshparvar, A.R. Shamshiri, Comparison of lateral window and osteotome techniques in sinus augmentation: histological and histomorphometric evaluation, J. Dent. 9 (3) (2012) 237-246.

[25] N.S. Aboelsaad, M. Soory, L.M.A. Gadalla, et al., Effect of soft laser and bioactive glass on bone regeneration in the treatment of infra-bony defects (a clinical study), Lasers Med. Sci. 24 (3) (2009) 0387-0395.

[26] L.B. Pinheiro, M.E.M.M. Gerbi, Photoengineering of bone repair processes, Photomed. Laser Surg. 24 (2) (2006) 169-178.

[27] N.S. AboElsaad, M. Soory, L.M. Gadalla, LI. Ragab, S. Dunne, K.R. Zalata, C. Louca, Effect of soft laser and bioactive glass on bone regeneration in the treatment of bone defects (an experimental study), Lasers Med. Sci. 24 (4) (2009) 527-533.

[28] U. Oron, T. Yaakobi, A. Oron, G. Hayam, L. Gepstein, O. Rubin, Attenuation of infarct size in rats and dogs after myocardial infarction by low energy laser irradiation, Lasers Surg. Med. 28 (2011) 204-211.

[29] J.W. Chen, Y.C. Zhou, Effect of low level carbon dioxide laser radiation on biochemical metabolism of rabbit mandibular bone callus, Laser Therapy 2 (1989) 83-87.

[30] P.V. Peplow, T.Y. Chung, G.D. Baxter, Laser photobiomodulation of proliferation of cells in culture: a review of human and animal studies, Photomed. Laser Surg. 28 (1) (2010) S3-40.

[31] C.R. Tim, P.S. Bossini, H.W. Kido, I. Malavazi, M.R. von Zeska Kress, M.F. Carazzolle, N.A. Parizotto, A.C. Rennó, Effects of low-level laser therapy on the expression of osteogenic genes during the initial stages of bone healing in rats: a microarray analysis, Lasers Med. Sci. 30 (9) (2015) 2325-2333.

[32] P.C. Silveira, L.A. Silva, D.B. Fraga, T.P. Freitas, E.L. Streck, R. Pinho, Evaluation of mitochondrial respiratory chain activity in muscle healing by low-level laser therapy, J. Photochem. Photobiol. B Biol. 95 (2) (2009) 89-92.

[33] D. Barbosa, R.A. de Souza, M. Xavier, F. da Silva, E.Â. Arisawa, A.G.B. Villaverde, Effects of low-level laser therapy (LLLT) on bone repair in rats: optical densitometry analysis, Lasers Med. Sci. 28 (2) (2013) 651-656.

[34] R.A. Nicolau, V. Jorgetti, J. Rigau, M.T.T. Pacheco, L.M. dos Reis, R.A. Zangaro, Effect of low-power GaAIAs laser (660 $\mathrm{nm}$ ) on bone structure and cell activity: an experimental animal study, Lasers Med. Sci. 18 (2) (2003) 89-94.

[35] R. Ewers, W. Goriwoda, C. Schopper, D. Moser, E. Spassova, Histologic findings at augmented bone areas supplied with two different bone substitute materials combined with sinus floor lifting, Clin. Oral Implants Res. 15 (1) (2004) 96-100.

[36] J.P. da Silva, M.A. da Silva, A.P.F. Almeida, I. Lombardi Junior, A.P. Matos, Laser therapy in the tissue repair process: a literature review, Photomed. Laser Surg. 28 (1) (2010) 17-21.

[37] R.R. Obradović, L.G. Kesić, S. Pesevska, Influence of low-level laser therapy on biomaterial osseointegration: a mini-review, Lasers Med. Sci. 24 (3) (2009) 447-451.

[38] V.G. Garcia, A.S. Sahyon, M. Longo, L.A. Fernandes, E.C. Gualberto Junior, V.C. Novaes, E. Ervolino, J.M. de Almeida, L.H. Theodoro, Effect of LLLT on autogenous bone grafts in the repair of critical size defects in the calvaria of immunosuppressed rats, J. Craniomaxillofac. Surg. 42 (7) (2014) 1196-1202.

[39] M. Khadra, H.J. Ronold, S.P. Lyngstadaas, J.E. Ellingsen, H.R. Haanæs, Low-level laser therapy stimulates bone-implant interaction: an experimental study in rabbits, Clin. Oral Implants Res. 15 (2004) 325-332.

[40] C. Kilkenny, W.J. Browne, I.C. Cuthill, M. Emerson, D.G. Altman, Improving bioscience research reporting: the ARRIVE guidelines for reporting animal research, J. Pharmacol. Pharmacother. 1 (2010) 94-99.

[41] V.G. Garcia, J.M. da Conceição, L.A. Fernandes, J.M. de Almeida, M.J. Nagata, A.F. Bosco, L.H. Theodoro, Effects of LLLT in combination with bisphosphonate on bone healing in critical size defects: a histological and histometric study in rat calvaria, Lasers Med. Sci. 28 (2) (2013) 407-414

[42] M.R. Messora, M.J. Nagata, R.C. Mariano, R.C. Dornelles, S.R. Bomfim, S.E. Fucini, et al., Bone healing in critical-size defects treated with platelet-rich plasma: a histologic and histometric study in rat calvaria, J. Periodontal Res. 43 (2) (2008) 217-223.

[43] P.P. Spicer, J.D. Kretlow, S. Young, J.A. Jansen, F.K. Kasper, A.G. Mikos, Evaluation of bone regeneration using the rat critical size calvarial defect, Nat. Protoc. 7 (10) (2012) 1918-1929.

[44] M.T. Rodrigues, C.L. Cardoso, P.S. Carvalho, T.M. Cestari, M. Feres, G.P. Garlet, et al., Experimental alveolitis in rats: microbiological, acute phase response and histometric characterization of delayed alveolar healing, J. Appl. Oral Sci. 19 (3) (2001) 260-268

[45] K. Schmidt-Bleek, H. Schell, N. Schulz, P. Hoff, C. Perka, F. Buttgereit, H.D. Volk, J. Lienau, G.N. Duda, Inflammatory phase of bone healing initiates the regenerative healing cascade, Cell Tissue Res. 347 (3) (2012) 567-573.

[46] A.E. Vieira, C.E. Repeke, B. Ferreira Junior Sde, Colavite PM, Biguetti CC, Oliveira RC, Assis GF, R. Taga, Trombone AP, Garlet GP, Intramembranous bone healing process subsequent to tooth extraction in mice: micro-computed tomography, histomorphometric and molecular characterization, PLoS One 10 (5) (2015) e0128021.

[47] Z. Lalani, M. Wong, E.M. Brey, A.G. Mikos, P.J. Duke, Spatial and temporal localization of transforming growth factor-beta1, bone morphogenetic protein-2, and plateletderived growth factor-A in healing tooth extraction sockets in a rabbit model, J. Oral Maxillofac. Surg. 61 (9) (2003) 1061-1072.

[48] R. Dimitriou, E. Tsiridis, P.V. Giannoudis, Current concepts of molecular aspects of bone healing, Injury 36 (12) (2005) 1392-1404.

[49] K. Tsuji, A. Bandyopadhyay, B.D. Harfe, K. Cox, S. Kakar, L. Gerstenfeld, T. Einhorn, C.J. Tabin, V. Rosen, BMP2 activity, although dispensable for bone formation, is required for the initiation of fracture healing, Nat. Genet. 38 (12) (2006) 1424-1429.

[50] E. Tsiridis, N. Upadhyay, P. Giannoudis, Molecular aspects of fracture healing: which are the important molecules? Injury 38 (1) (2007) S11-S25.

[51] Z.S. Ai-Aql, A.S. Alagl, D.T. Graves, L.C. Gerstenfeld, T.A. Einhorn, Molecular mechanisms controlling bone formation during fracture healing and distraction osteogenesis, J. Dent. Res. 87 (2) (2008) 107-118. 
[52] A.J. Hussein, A.A. Alfars, M.A. Falih, A.N. Hassan, Effects of a low level laser on the acceleration of wound healing in rabbits, N. Amer. J. Med. Sci. 3 (4) (2011) 193-197.

[53] M. Giannelli, F. Chellini, C. Sassoli, F. Francini, A. Pini, R. Squecco, D. Nosi, D. Bani, S. Zecchi-Orlandini, L. Formigli, Photoactivation of bone marrow mesenchymal stromal cells with diode laser: effects and mechanisms of action, J. Cell. Physiol. 228 (1) (2013) 172-181.

[54] M. Xu, T. Deng, F. Mo, B. Deng, W. Lam, P. Deng, X. Zhang, S. Liu, Lowintensity pulsed laser irradiation affects RANKL and OPG mRNA expression in rat calvarial cells, Photomed. Laser Surg. 27 (2) (2009) 309-315.

[55] R.R. Obradović, L.G. Kesić, S. Pesevska, Influence of low-level laser therapy on biomaterial osseointegration: a mini-review, Lasers Med. Sci. 24 (3) (2009) 447-451.

[56] G. Tomoaia, R.D. Pasca, On the collagen mineralization. A review, Clujul Med. 88 (1) (2015) 15-22.

[57] K. Kawasaki, N. Shimizu, Effects of low-energy laser irradiation on bone remodeling during experimental tooth movement in rats, Lasers Surg. Med. 26 (3) (2000) 282-291.

[58] A.N. Silva Júnior, A.L. Pinheiro, M.G. Oliveira, R. Weismann, L.M. Ramalho, R.A. Nicolau, Computerized morphometric assessment of the effect of low-level laser therapy on bone repair: an experimental animal study, J. Clin. Laser Med. Surg. 20 (2) (2002) 83-87.

[59] M.E. Gerbi, A.L. Pinheiro, C. Marzola, A. Limeira Júnior Fde, Ramalho LM, Ponzi EA, Soares AO, Carvalho LC, Lima HV, Goncalves TO, Assessment of bone repair associated with the use of organic bovine bone and membrane irradiated at $830 \mathrm{~nm}$, Photomed. Laser Surg. 23 (4) (2005) 382-388.

[60] C.B. Lopes, A.L. Pinheiro, S. Sathaiah, J. Duarte, M. Cristinamartins, Infrared laser light reduces loading time of dental implants: a Raman spectroscopic study, Photomed. Laser Surg. 23 (1) (2005) 27-31.

[61] A.L. Pinheiro, F. Limeira Júnior, de A. Gerbi ME, Ramalho LM, C. Marzola, Ponzi EA, Soares AO, De Carvalho LC, Lima HC, Gonçlves TO, Effect of 830-nm laser light on the repair of bone defects grafted with inorganic bovine bone and decalcified cortical osseus membrane, J. Clin. Laser Med. Surg. 21 (5) (2003) 301-306.

[62] J.B. Weber, A.L. Pinheiro, M.G. de Oliveira, F.A. Oliveira, L.M. Ramalho, Laser therapy improves healing of bone defects submitted to autologous bone graft, Photomed. Laser Surg. 24 (1) (2006) 38-44.

[63] A.P. Lirani-Galvão, V. Jorgetti, O.L. da Silva, Comparative study of how low-level laser therapy and low-intensity pulsed ultrasound affect bone repair in rats, Photomed. Laser Surg. 24 (6) (2006) 735-740.

[64] A.L. Pinheiro, Gerbi M.E. Martinez, F. de Assis L Jr., Carneiro PEA, Marques AM, Carvalho CM, de Carneiro SR., Oliveira PC, M. Nóia, Ramalho LM, Bone repair following bone grafting hydroxyapatite guided bone regeneration and infra-red laser photobiomodulation: a histological study in a rodent model, Lasers Med. Sci. 24 (2) (2009) 234-240.

[65] N. Jakse, M. Payer, S. Tangl, A. Berghold, R. Kirmeier, M. Lorenzoni, Influence of lowlevel laser treatment on bone regeneration and osseointegration of dental implants following sinus augmentation. An experimental study on sheep, Clin. Oral Implants Res. 4 (2007) 517-524.

[66] R. Obradović, L. Kesić, D. Mihailović, N. Ignjatović, D. Uskoković, Comparative efficacy analysis of biomaterials and soft lasers in repair of bone defects, J. Oral Laser Appl. 7 (2007) 161-166.
[67] M.E. Gerbi, A.M. Marques, L.M. Ramalho, E.A. Ponzi, C.M. Carvalho, C. Santos Rde, Oliveira PC, M. Nóia, Pinheiro AL, Infrared laser light further improves boné healing when associated with bone morphogenic proteins: an in vivo study in a rodent model, Photomed. Laser Surg. 26 (1) (2008) 55-60.

[68] C.B. Lopes, M.T. Pacheco, L. Silveira Jr., J. Duarte, M.C. Cangussú, A.L. Pinheiro, The effect of the association of NIR laser therapy BMPs, and guided bone regeneration on tibial fractures treated with wire osteosynthesis: Raman spectroscopy study, J. Photochem. Photobiol. B Biol. 14 (89(2-3)) (2007) 125-130.

[69] S. Rochkind, G. Kogan, E.G. Luger, K. Salame, E. Karp, M. Graif, J. Weiss, Molecular structure of the bony tissue after experimental trauma to the mandibular region followed by laser therapy, Photomed. Laser Surg. 22 (3) (2004) 249-253.

[70] G. Brunel, P. Piantoni, F. Elharar, E. Benqué, P. Marin, S. Zahedi, Regeneration of rat calvarial defects using a bioabsorbable membrane technique: influence of collagen crosslinking, J. Periodontol. 67 (12) (1996) 1342-1348.

[71] S.C. Lim, M.J. Lee, H.H. Yeo, Effects of various implant materials on regeneration of calvarial defects in rats, Pathol. Int. 50 (8) (2000) 594-602.

[72] J.W. Frame, A convenient animal model for testing bone substitute materials, J. Oral Maxillofac. Surg. 38 (3) (1980) 176-180.

[73] C. Bosch, B. Melsen, K. Vargervik, Importance of the critical size bone defect in testing bone-regenerating materials, J. Craniomaxillofac. Surg. 9 (1998) 310-316.

[74] J.P. Schmitz, J.O. Hollinger, The critical size defect as an experimental model for craniomandibulofacial nonunions, Clin. Orthop. Relat. Res. 29 (205) (1986) 9-308.

[75] Bone Nanci, Ten Cate's Oral Histology: Development, Structure, and Function, Elsevier Health Sciences, 2008 108-140.

[76] G. Araújo, M. Sonohara, R. Hayacibara, G. Cardaropoli, J. Lindhe, Lateral ridge augmentation by the use of grafts comprised of autologous bone or a biomaterial. An experiment in the dog, J. Clin. Periodontol. 29 (12) (2002) 1122-1131.

[77] Maiorana, M. Beretta, S. Salina, F. Santoro, Reduction of autogenous bone graft resorption by means of bio-oss coverage: a prospective study, Int. J. Period. Restor. Dentis. 25 (1) (2005) 19-25.

[78] Rickert, S. Sauerbier, H. Nagursky, D. Menne, A. Vissink, G.M. Raghoebar, Maxillary sinus floor elevation with bovine bone mineral combined with either autogenous bone or autogenous stem cells: a prospective randomized clinical trial, Clin. Oral Implants Res. 22 (3) (2011) 251-258.

[79] Wildburger, M. Payer, N. Jakse, D. Strunk, N. Etchard-Liechtenstein, S. Sauerbier, Impact of autogenous concentrated bone marrow aspirate on bone regeneration after sinus floor augmentation with a bovine bone substitute - a split-mouth pilot study, Clin. Oral Implants Res. 25 (10) (2014) 1175-1181.

[80] B.E. Houser, J.T. Mellonig, M.A. Brunsvold, D.L. Cochran, R.M. Meffert, M.E. Alder, Clinical evaluation of anorganic bovine bone xenograft with a bioabsorbable collagen barrier in the treatment of molar furcation defects, Int. J. Period. Restor. Dentist. 21 (2) (2001) 161-169.

[81] M.R. Norton, E.W. Odell, I.D. Thompson, R.J. Cook, Efficacy of bovine bone mineral for alveolar augmentation: a human histologic study, Clin. Oral Implants Res. 14 (6) (2003) 775-783. 